Original Article

\title{
Ultrasound evaluation of the symmetry of abdominal muscles in mild adolescent idiopathic scoliosis
}

\author{
Pawel Linek, PhD ${ }^{1)^{*}}$, Edward Saulicz, PhD, DSc ${ }^{1,2)}$, Tomasz Wolny, $\mathrm{PhD}^{1,2)}$, \\ Andrzej Myśliwiec, $\mathrm{PhD}^{1)}$, Anna Gogola, $\mathrm{PhD}^{1)}$ \\ 1) Department of Kinesitherapy and Special Methods in Physiotherapy, The Jerzy Kukuczka Academy \\ of Physical Education: 40-065 Mikolowska 72B, Katowice, Poland \\ 2) Department of Physiotherapy, Academy of Business, Poland
}

\begin{abstract}
Purpose] The objective of the study was to evaluate the symmetry of the thickness of the abdominal muscles at rest and while standing in patients with adolescent idiopathic scoliosis. [Subjects and Methods] An ultrasound assessment was performed of the side-to-side differences of the external oblique (EO), internal oblique (IO), and transversus abdominalis ( $\mathrm{Tr} A)$ muscles in the supine and standing positions in adolescent idiopathic scoliosis (AIS) and control groups. [Results] In the AIS group, $64.3 \%$ of the patients had left scoliosis with a mean Cobb angle of $10.7^{\circ}$, and $35.7 \%$ of the patients had right scoliosis with a mean Cobb angle of $10^{\circ}$. In the supine position, the thickness asymmetry of the TrA was greater in the AIS compared with the control group by an average of $14 \%$ (95\% CI 3.9-24.2). [Conclusion] Among the abdominal muscles examined, patients with AIS exhibited more asymmetry only for the TrA. In the standing position, the TrA was as symmetric in the patients as in the control group. Mild scoliosis has no impact on the symmetry of the thickness of the OE and OI in the supine and standing positions. The direction of curvature had no effect on the symmetry of the abdominal muscles studied.

Key words: Adolescent, Idiopathic scoliosis
\end{abstract}

(This article was submitted Jul. 23, 2014, and was accepted Sep. 2, 2014)

\section{INTRODUCTION}

Idiopathic scoliosis is a three-dimensional spine deformity that frequently occurs during adolescence (adolescent idiopathic scoliosis: AIS); however, its aetiology remains unclear and is probably multifactorial ${ }^{1)}$. Kuo et al. ${ }^{2)}$ showed that patients with AIS demonstrate asymmetric muscle activation during an anticipated perturbation and detected significant differences in postural control in the AIS group. According to Panjabi's theory, optimal postural control (postural stability) depends on cooperation between the passive subsystem and active subsystem, which are under the permanent control of the central nervous system ${ }^{3)}$. In the active subsystem, both the paravertebral muscles and abdominal muscles, whose activities depend on posture and motor tasks, are important ${ }^{4}$. The transversus abdominalis $(\operatorname{Tr} A)$, which is part of the deep muscular cylinder and ensures the stabilization of the spine at the segmental level, is thought to play a special role ${ }^{5}$. Furthermore, the TrA and the abdominal oblique internal (OI) muscles affect the stabiliza-

*Corresponding author. Paweł Linek (E-mail: linek. fizjoterapia@vp.pl)

C2015 The Society of Physical Therapy Science. Published by IPEC Inc This is an open-access article distributed under the terms of the Creative Commons Attribution Non-Commercial No Derivatives (by-ncnd) License $<$ http://creativecommons.org/licenses/by-nc-nd/3.0/>. tion of the sacroiliac joints, which ensures the stability of the lumbo-pelvic-hip complex ${ }^{6}$; over the entire length of the lateral raphe, the $\operatorname{TrA}$ is attached to the thoracolumbar fascia ${ }^{7)}$, the tension of which significantly increases the system's rigidity and spine-stabilizing forces ${ }^{8)}$, thus controlling movement (rotations and translations) in a given segment ${ }^{9}$. As we can see, the sacroiliac joints, thoracolumbar fascia, and abdominal muscles can contribute to better postural control, which is disrupted in AIS patients ${ }^{2)}$. The results of a previous study demonstrated that stabilization exercise effectively improves balance, suggesting that such exercise can be clinically used for patients with AIS to improve their postural control ${ }^{10)}$.

There are only few studies in the literature regarding the functions of abdominal muscles in patients with AIS ${ }^{11,12)}$. In the only existing studies about side-to-side differences in abdominal muscle thickness, Rankin et al. and Mannion et al. showed some level of asymmetry in adults with no low back pain problems ${ }^{13,14)}$, but in their studies they did not take into account possible spine deviations. Therefore, an evaluation of the thickness of the abdominal muscles at rest and while standing was undertaken in this study in adolescents with mild AIS compared with a control group.

\section{SUBJECTS AND METHODS}

Two groups participated in the study: 42 adolescents without scoliosis (control group) and 42 patients with AIS 
(AIS group). The participants in the control group were recruited randomly from public schools, whereas the patients with AIS were from a corrective exercise center. The control group included individuals with no signs of scoliosis upon screening and no trunk rotation in Adams' test using a scoliometer. The AIS group included individuals who had been diagnosed by an orthopedist as having single-curve idiopathic scoliosis, in which the apex was at the level of Th12, L1, or at the intervertebral Th12/L1 disc level (confirmed by X-ray), i.e., thoracolumbar scoliosis according to Ponseti's classification. Both groups were similar in age (10-16 years). All subjects were free of any documented spinal surgery, and any cardiovascular or neurologic disease. The participants and their parents gave informed consent before the investigation. The study was also approved by the local ethics committee.

A real-time ultrasound B-scanner (Mindray DP-6600 Digital Ultrasonic Diagnostic Imaging System, Mindray Medical Corp., Redmont, WA, USA) with a $60 \mathrm{~mm}$ wide 75L38EA linear array transducer $(5.0 / 7.5 / 10 \mathrm{MHz})$ was used to obtain images of the muscles. The penetration depth was $5.39 \mathrm{~cm}$ at a sampling frequency of $7.5 \mathrm{MHz}$. The transducer was always placed on the anterolateral wall of the abdomen, between the iliac crest and the inferior boundary of the 12th rib, and perpendicular to the longitudinal axis of the body. The transducer was also always placed at the same altitude and distance from the umbilicus during examination on the right and left sides of the body of a subject. Ultrasound is a reliable tool for evaluating abdominal muscles in both adult and adolescent populations ${ }^{15-18)}$.

Measurements of the thickness of the muscles were collected in the supine and standing positions. Three measurements were performed alternately (right side, left side) for each position and each side, always starting with the right side. The thickness was measured in millimeters at the end of normal expiration. All images were captured and measured off-line. Each measurement was performed in the middle of the ultrasound image perpendicular to the course of the muscles under investigation. For analysis, the mean value of three measurements performed on the right and left sides was taken, and the percentage difference in thickness was calculated for each muscle (OE, OI, and $\mathrm{TrA}$ ) according to the following formula: muscle thickness difference $=[($ right side - left side) / (right side) $] \times 100$.

Analysis of variance was used to compare the percentage difference in muscle thickness, with one between factor (control vs. AIS group or direction of curvature in AIS) and one within factor (body position). The t-test for independent measurements was used to compare basic parameters (age, height, body weight) in the population examined. Differences were considered significant when $\mathrm{p}<0.05$.

\section{RESULTS}

The data on age, height, and weight are presented in Table 1. There were no significant differences between the two groups for any of these parameters. In $64.3 \%$ of cases, left scoliosis was detected, and its mean Cobb angle was $10.7^{\circ}$. The other $35.7 \%$ of subjects had right scoliosis with a mean value of $10^{\circ}$. No significant differences in Cobb angle were detected between right and left scoliosis $(p=0.60)$ by t-test.

No significant differences in the percentage asymmetry in the OE and OI muscle thickness were observed between the control and AIS groups $(p>0.05)$. In relation to TrA, significant differences were observed in the interaction between groups and body positions $(\mathrm{p}<0.03)$. Based on the mean values, it was demonstrated that the TrA was thicker by an average of $14 \%$ (95\% CI 3.9-24.2) on the left side in the AIS group compared with the control group, but only in the supine position). No significant differences in muscle thickness asymmetry were observed between right and left scoliosis in the AIS group ( $>00.05)$. Table 2 shows the mean values of all measurements.

\section{DISCUSSION}

The comparison of the OE, OI, and TrA muscle thicknesses on both sides in the resting supine position and in the standing position in AIS patients presented here is the first

Table 1. The mean (SD) or group size (\%) in both groups

\begin{tabular}{lrr}
\hline \multirow{2}{*}{ Parameter } & \multicolumn{2}{c}{ Group } \\
\cline { 2 - 3 } & \multicolumn{1}{c}{$\begin{array}{c}\text { Control } \\
(\mathrm{n}=42)\end{array}$} & $\begin{array}{c}\text { AIS } \\
(\mathrm{n}=42)\end{array}$ \\
\hline Age $(\mathrm{yrs})$ & $12.4(1.54)$ & $12.5(1.77)$ \\
Weight $(\mathrm{kg})$ & $48.1(12.7)$ & $46.9(11.8)$ \\
Height $(\mathrm{cm})$ & $158.4(11.1)$ & $157.5(12.3)$ \\
Number of males $(\%)$ & $27(64.3)$ & $27(64.3)$ \\
\hline
\end{tabular}

AIS: adolescent idiopathic scoliosis

Table 2. Comparison of the mean (SD) percent changes (\%) in thickness of muscles between body sides in both groups

\begin{tabular}{cccccc}
\hline \multirow{2}{*}{$\begin{array}{l}\text { Muscles } \\
\text { percent change (\%) }\end{array}$} & \multirow{2}{*}{ Position } & \multicolumn{4}{c}{ Groups } \\
\cline { 3 - 5 } & & Controls & AIS & \multicolumn{1}{c}{ AIS (R) } & AIS (L) \\
\hline EO & Supine & $3.25(18.1)$ & $11.1(15.21)$ & $15.1(16.3)$ & $8.94(14.4)$ \\
EO & Standing & $-2.34(11.9)$ & $4.80(18.7)$ & $8.82(12.7)$ & $2.57(21.3)$ \\
IO & Supine & $6.14(17.3)$ & $0.46(14.4)$ & $-0.92(17.4)$ & $1.23(12.8)$ \\
IO & Standing & $-3.20(25.3)$ & $2.67(18.2)$ & $0.15(20.5)$ & $4.07(17.1)$ \\
TrA & Supine & $1.52(11.9)$ & $-12.50(17.8)$ & $-12.6(20.0)$ & $-12.4(16.9)$ \\
TrA & Standing & $-2.45(2.37)$ & $-4.82(20.8)$ & $-8.53(21.3)$ & $-2.77(20.8)$ \\
\hline
\end{tabular}

AIS: adolescent idiopathic scoliosis; (R): only with right scoliosis; (L): only with left scoliosis 
study of this type. A review of the literature demonstrated that previous studies of such differences in abdominal muscle thickness were carried out only in adult populations ${ }^{13,14)}$.

In the current study, we evaluated the percentage difference in muscle (OE, OI, TrA) thickness between the right and left sides, rather than the thickness of the muscle per se. The results obtained indicate that, in the supine position, the asymmetry of the TrA in AIS patients was greater than in the control group. However, some asymmetry of all muscles studied was also observed in the healthy control group, with mean values of $1.5 \%$ for the $\operatorname{TrA}, 2.2 \%$ for the $\mathrm{OE}$, and $6.1 \%$ for the OI. In studies conducted by Mannion et al. and Rankin et al., the differences in the thickness of the muscles studied were between $11 \%$ and $26 \%$ in presumably healthy adult populations with no lower back pain ${ }^{13,14)}$. The exclusion criteria in the aforementioned studies were similar to those in the current report. A significant exception (in addition to age) was the criterion excluding individuals with any spine deviation from the control group. Should any scolioses be taken into account when examining an adult population? That this should be done is suggested in part by the fact that in patients with AIS with low-grade single curve scoliosis, the mean percentage difference for the TrA was $14 \%$ and was significantly higher than that in the control group. Thus, lowgrade scoliosis could be used in an attempt to explain such differences in TrA thickness even in adult healthy persons. On the other hand, the demonstrated asymmetry in the $\operatorname{Tr} A$ thickness could result from adaptive changes associated with motor activity or the repetitive activities of everyday life. In this report, the activity of the people studied and whether they were exposed to asymmetrical demands were not considered: patients with scoliosis were recruited from the physical therapy center where they participated in exercises designed to correct their posture. It may be that the asymmetry demonstrated is not the result of spine scoliosis but simply the result of adaptation to specific repeated exercises. This is a significant limitation. Thus, it seems justifiable to check to what extent a specific motor activity (especially asymmetric) can affect the symmetry of the thickness of the abdominal muscles in child and adult populations.

It is interesting that the $\operatorname{TrA}$ is more symmetrical in the standing position. Unfortunately, no analysis of the side-toside differences in the standing position has been performed in any previous studies, so it is therefore difficult to explain why the TrA shows greater asymmetry only in the supine position. It is likely that gravity is a significant factor here, because, according to Bergmark's classification, the TrA is a local antigravity muscle ${ }^{19)}$. Some investigators suggest that the limited impact of gravity has a destructive effect on antigravity muscles ${ }^{20)}$. It may be that in patients with AIS, the TrA on one side undergoes a functional change from maintaining tone to performing a motor function, but only when gravity is limited, e.g., in the supine position. On the other hand, a lack of differences in the TrA in the fully extended position could be caused by the fact that patients were asked to assume an extended position placing equal load on both lower limbs. In the work by Reeve and Dilley, the authors demonstrated that the thickness of this muscle in the corrected position is greater than that in the sway standing position ${ }^{21)}$. In corrected positions, the TrA may function similarly in both groups studied, and any differences may only be observed during those activities that are more involuntary. Therefore, it seems important to determine at this point to what extent placing weight on the lower limbs affects the thickness of the abdominal muscles. The results of this work are also partly consistent with the results described by Kim et al., who showed that the asymmetry in the TrA muscle thickness decreased under dynamic conditions ${ }^{22)}$. Of course, standing is more dynamic than the supine position.

Can changes in the TrA lead to scoliosis? From the purely anatomical standpoint, the answer is yes, because it attaches to the thoracolumbar fascia over the entire length of the lateral raphe and can therefore increase its tension in the middle and inferior portions ${ }^{7}$. Some investigators believe that the tension of this fascia affects spine stability ${ }^{23}$ and contributes to the control of movements (rotation and translation) within the segment in which it induces transversal forces ${ }^{9)}$. However, the results of the current report do not support those suggestions because, regardless of the direction of scoliosis, no significant differences in the TrA or other muscle thickness were observed. Based on these data, it is difficult to believe that the two different types of scoliosis are induced by identical asymmetric tone distributions.

In conclusion, among the abdominal muscles examined, patients with AIS exhibit more asymmetry only in the TrA. The thickness of the TrA was greater on the left side in the supine position in patients with AIS. In the standing position, the TrA was as symmetrical as in the control group. Mild scoliosis had no impact on the symmetry of the thickness of the $\mathrm{OE}$ and $\mathrm{OI}$ in supine and standing positions. The direction of curvature had no effect on the symmetry of the abdominal muscles studied.

\section{REFERENCES}

1) Kouwenhoven JW, Castelein RM: The pathogenesis of adolescent idiopathic scoliosis: review of the literature. Spine, 2008, 33: 2898-2908. [Medline] [CrossRef]

2) Kuo FC, Hong CZ, Lai CL, et al.: Postural control strategies related to anticipatory perturbation and quick perturbation in adolescent idiopathic scoliosis. Spine, 2011, 36: 810-816. [Medline] [CrossRef]

3) Panjabi MM: The stabilizing system of the spine. Part I. Function, dysfunction, adaptation, and enhancement. J Spinal Disord, 1992, 5: 383-389, discussion 397. [Medline] [CrossRef]

4) McGill SM, Grenier S, Kavcic N, et al.: Coordination of muscle activity to assure stability of the lumbar spine. J Electromyogr Kinesiol, 2003, 13: 353-359. [Medline] [CrossRef]

5) Hodges PW: Is there a role for transversus abdominis in lumbo-pelvic stability? Man Ther, 1999, 4: 74-86. [Medline] [CrossRef]

6) Snijders CJ, Vleeming A, Stoeckart R: Transfer of lumbosacral load to iliac bones and legs Part 1: Biomechanics of self-bracing of the sacroiliac joints and its significance for treatment and exercise. Clin Biomech (Bristol, Avon), 1993, 8: 285-294. [Medline] [CrossRef]

7) Bogduk N, Macintosh JE: The applied anatomy of the thoracolumbar fascia. Spine, 1984, 9: 164-170. [Medline] [CrossRef]

8) Tesh KM, Dunn JS, Evans JH: The abdominal muscles and vertebral stability. Spine, 1987, 12: 501-508. [Medline] [CrossRef]

9) Hodges P, Kaigle Holm A, Holm S, et al.: Intervertebral stiffness of the spine is increased by evoked contraction of transversus abdominis and the diaphragm: in vivo porcine studies. Spine, 2003, 28: 2594-2601. [Medline] [CrossRef]

10) Shin SS, Lee YW, Song CH: Effects of Lumbar Stabilization Exercise on Postural Sway of Patients with Adolescent Idiopathic Scoliosis during Quiet Sitting. J Phys Ther Sci, 2012, 24: 211-215. [CrossRef]

11) Linek P, Saulicz E, Kuszewski M, et al.: Ultrasound assessment of the abdominal muscles at rest and during the ASLR test among adolescents with scoliosis. J Spinal Disord Tech, 2014. [CrossRef]. [Medline] 
12) Yang HS, Yoo JW, Lee BA, et al.: Inter-tester and intra-tester reliability of ultrasound imaging measurements of abdominal muscles in adolescents with and without idiopathic scoliosis: a case-controlled study. Biomed Mater Eng, 2014, 24: 453-458. [Medline]

13) Rankin G, Stokes M, Newham DJ: Abdominal muscle size and symmetry in normal subjects. Muscle Nerve, 2006, 34: 320-326. [Medline] [CrossRef]

14) Mannion AF, Pulkovski N, Toma V, et al.: Abdominal muscle size and symmetry at rest and during abdominal hollowing exercises in healthy control subjects. J Anat, 2008, 213: 173-182. [Medline] [CrossRef]

15) Linek P, Saulicz E, Wolny T, et al.: Reliability of B-mode sonography of the abdominal muscles in healthy adolescents in different body positions. J Ultrasound Med, 2014, 33: 1049-1056. [Medline] [CrossRef]

16) Park SD: Reliability of ultrasound imaging of the transversus deep abdominial, internal oblique and external oblique muscles of patients with low back pain performing the drawing-in maneuver. J Phys Ther Sci, 2013, 25: 845-847. [Medline] [CrossRef]

17) Otani $Y$, Itotani $K$, Maeda N, et al.: Reliability of the deep abdominal muscle thickness measurements using ultrasonography in normal subjects.
Phys Ther Sci, 2011, 23: 357-359. [CrossRef]

18) Linek P, Saulicz E, Wolny T, et al.: Intra-rater reliability of B-mode ultrasound imaging of the abdominal muscles in healthy adolescents during the active straight leg raise test. PM R, 2014. [CrossRef]. [Medline]

19) Bergmark A: Stability of the lumbar spine. A study in mechanical engineering. Acta Orthop Scand Suppl, 1989, 230: 1-54. [Medline] [CrossRef]

20) Richardson CA: the health of the human skeletal system for weight bearing against gravity: the role of deloading the musculo-skeletal system in the development of musculoskeletal injury. J Gravit Physiol, 2002, 9: 7-10. [Medline]

21) Reeve A, Dilley A: Effects of posture on the thickness of transversus abdominis in pain-free subjects. Man Ther, 2009, 14: 679-684. [Medline] [CrossRef]

22) Kim Y, Shim JK, Son J, et al.: A neuromuscular strategy to prevent spinal torsion: backward perturbation alters asymmetry of transversus abdominis muscle thickness into symmetry. Gait Posture, 2013, 38: 231-235. [Medline] [CrossRef]

23) Gracovetsky S, Farfan H, Helleur C: The abdominal mechanism. Spine, 1985, 10: 317-324. [Medline] [CrossRef] 